\title{
ENDÜSTRİ 4.0 TEKNOLOJİK OLGUNLUK DÜZEYİNİN ANALİTİK HİYERARŞİ PROSESİ İLE MODELLENMESİ: GIDA VE İÇECEK IMMALAT SEKTÖRÜ ÖRNEĞİ
}

Tuğba SARI 1

$\ddot{O Z Z}$

Anahtar Kelimeler:

Endüstri 4.0,

Olgunluk Modeli,

AHP,

Analitik Hiyerarşi Prosesi,

Gıda ve İçecek Imalat Sektörü,

\author{
JEL Kodlari: \\ M11
}

Keywords:

Industry 4.0 Maturity AHP Model

Analytic Hierarchy Process
$18 / 08 / 2020$

$21 / 09 / 2020$

$25 / 09 / 2020$

Endüstri 4.0 dönüşümü, bileşenlerini oluşturan temel teknolojiler ile imalat sanayine, mevcut operasyonları ve süreçleri kökten değiştirecek yenilikler getirmektedir. Gıda ve içecek imalat sektöründe beklenen başlica değişimler, artan verimlilik; artan gıda güvenliği; yüksek gıda kalitesi ve azalan atık miktarı olarak sıralanabilir. İşletmelerin Endüstri 4.0'dan elde edeceği faydayı maksimuma çıkarmak için, uygulamaların ölçülebilir ve karşılaştırılabilir olması gerekir. Endüstri 4.0 olgunluk modelleri dönüşüm sürecinde standartlaştırma ve karşılaştırma için önemli göstergeler sunmaktadır. Bu çalışmada temel Endüstri 4.0 teknolojilerinin kullanımın Analitik Hiyerarşi Prosesi yöntemi ile değerlendiren, sektöre özel bir olgunluk modeli önerilmektedir. Çalışmanın sonuçlarına göre gıda ve içecek imalat sektörü için en önemli teknolojiler Otonom Robotlar ve Siber Güvenlik olarak belirlenmiştir. Bu iki teknolojiyi, strasıyla Büyük Veri Analitiği ve Eklemeli Imalat Sistemleri takip etmektedir. Çalışmada bir Endüstri 4.0 olgunluk ölçeği sunulmuş olup, örnek uygulama ile gıda imalatçısı bir işletmenin bu ölçek üzerinden Endüstri 4.0 olgunluğu hesaplanmıştır.

JEL Codes: $\quad$ M11

\footnotetext{
${ }^{1}$ Dr. Öğr. Üyesi, Konya Gıda ve Tarım Üniversitesi, tugba.sari@gidatarim.edu.tr, $\quad \underline{\text { https://orcid.org/0000-0002-9536-5541 }}$
} 


\section{EXTENDED ABSTRACT}

\section{DEVELOPMENT OF AN INDUSTRY 4.0 MATURITY MODEL BY ANALYTIC HIERARCHY PROCESS: CASE OF FOOD AND BEVERAGE MANUFACTURING SECTOR}

\section{LITERATURE}

Industry 4.0 transformation brings innovations that will radically change the existing operations and processes in the manufacturing industry. Expected changes in the Food and beverage manufacturing industry are increased efficiency; increased food security; higher food quality, and decreased waste. In order to maximise the benefits of Industry 4.0, implementations must be measurable and comparable. Industry 4.0 maturity models provide useful tools for standardisation and comparison in the transformation process. There are two types of Industry 4.0 maturity models: (1) Holistic approaches such as the studies by Lichtblau et al. (2015), Schumacher et al. (2016 and 2019), Santos and Martinho (2019; and (2) Specific approaches such as the models by Commuzzi (2016), Leyh et al. (2017), and Nemeth et al. (2018). In this study, a sector-specific Industry 4.0 maturity model with the Analytical Hierarchy Process is proposed. This model focuses on essential Industry 4.0 technologies and their usage.

\section{DESIGN AND METHOD}

The purpose of the study is to develop a technology-oriented, sector-specific Industry 4.0 maturity model for evaluating Industry 4.0 maturity levels of manufacturing companies. Tabular representation of the proposed model is given in Table 1.

Table 1. Proposed Industry 4.0 Maturity Model

\begin{tabular}{|c|c|}
\hline \multicolumn{2}{|c|}{ Stage 1. Identifying maturity model criteria } \\
\hline Step 1.1 Literature survey & $\begin{array}{c}\text { Step 1.2 Selecting essential Industry } \\
4.0 \text { technologies as criteria }\end{array}$ \\
\hline \multicolumn{2}{|c|}{ Stage 2. Determining the weights of maturity model criteria } \\
\hline $\begin{array}{c}\text { Step 2.1 Gathering sector-related } \\
\text { Industry 4.0 data }\end{array}$ & $\begin{array}{c}\text { Step 2.1 Defining weights of } \\
\text { Industry } 4.0 \text { technologies via AHP }\end{array}$ \\
\hline \multicolumn{2}{|c|}{ Stage 3. Development of Industry 4.0 maturity model } \\
\hline \multirow{2}{|c|}{$\begin{array}{c}\text { Step 3.1 Defining a scale for } \\
\text { measurement }\end{array}$} & $\begin{array}{c}\text { Step 3.2 A case application in food } \\
\text { and beverage } \\
\text { manufacturing industry }\end{array}$ \\
\hline
\end{tabular}


The model is based on the usage of nine primary Industry 4.0 technologies which are: Augmented Reality, Cloud Computing, Big Data \& Analytics, Additive Manufacturing, Internet of Things, Autonomous Robots, Cyber Security, Simulation and System Integration. A group of experts are asked the relative importance degrees of each technology in the food and beverage manufacturing industry. The weight of each technology is calculated using AHP. An Industry 4.0 maturity scale is constructed for evaluation.

\section{FINDINGS AND DISCUSSION}

The results of the study reveal that the most critical technologies for the food and beverage manufacturing industry are Autonomous Robots and Cyber Security. These two technologies are followed by Big Data \& Analytics and Additive Manufacturing Systems, respectively. At the end of the study, Industry 4.0 maturity degree of a food manufacturing company is evaluated through the proposed model.

\section{CONCLUSION, RECOMMENDATIONS AND LIMITATIONS}

This model can be used as a useful self-assessment tool for Industry 4.0 maturity. It may be possible for companies to make comparisons and improvements by comparing themselves with acceptable practices in the industry. This scale also serves as a guide for small and medium-sized enterprises that have difficulty in accessing knowledge and in setting strategies for Industry 4.0 transformation. In future studies, the current maturity model can be adapted and applied to other manufacturing and service sectors. 


\section{GİRIŞ}

Günümüzde tüm dünyada her sektörü etkileyen ve yakın gelecekte etkilerini daha güçlü hissedecek olduğumuz baş döndürücü bir dijitalleşme deneyimi yaşıyoruz. 18. Yüzyılın sonlarında buhar gücünün kullanılması ile başlayan sanayi devrimleri, kitlesel üretim araçları ve üretimde otomasyon aşamalarından geçerek, yeni bir devriminin, diğer bir deyişle, dördüncü sanayi devriminin kapılarını aralamış durumdadir.

Endüstri 4.0 (E4.0) olarak da adlandırılan dördüncü sanayi devrimi, heterojen verilerin ve bilginin bütünleştirilip analiz edilmesini temel alan, siber-fiziksel sistemlere (CPS) dayalı üretim ortamları ile şekillenmektedir (Lu, 2017). Ürünleri internet özellikli hale getiren siber teknolojilerin bütünleştirilmesi, internet tabanlı teşhis, bakım, işletim vb. faaliyetlerin maliyet etkin ve verimli bir şekilde elde etmek için yenilikçi hizmetleri kolaylaştırır (Jazdi, 2014).

Endüstri 4.0, eklemeli imalat sistemleri ile tam zamanında ve düşük maliyetli üretim olanakları sunarken, aynı zamanda ürün ve hizmetlerin sanal ortamda simülasyon teknikleri ile test edilmesine de olanak verir (Yaşar ve Ulusoy, 2019). Endüstri 4.0' ın bir diğer faydası, üretim faaliyetlerinin çevre ve insan sağllğı açısından sürdürülebilirliğine olan pozitif etkisidir. Üretim faaliyetleri sırasında hammadde, enerji ve işgücü gibi kısıtlı kaynakların hızla tüketilmesi ve atıkların çevresel etkilerinin azaltılması sorunlarına Endüstri 4.0 dönüşümünün olumlu katkı yapacağı düşünülmektedir (Özenir ve Nakıboğlu, 2019). Düşük maliyet, yüksek verimlilik ve operasyonel esneklik odaklı firmaların, özellikle imalat teknolojileri boyutunda Endüstri 4.0 uygulamalarına öncelik vermesi gerekmektedir (Dalenogare vd., 2018).

\subsection{Endüstri 4.0 Teknolojileri}

İmalat sanayiini yakından etkileyen ve Endüstri 4.0 dönüşümünün temelini oluşturan teknolojiler dokuz ayrı başlık altında incelenebilir: artırılmış gerçeklik, bulut bilişim teknolojisi, büyük veri analitiği, eklemeli imalat sistemleri, nesnelerin interneti, otonom robotlar, siber güvenlik sistemleri, simülasyon ve sistem bütünleştirme (BCG, 2020). 
Fiziksel gerçek dünya ortamının, bilgisayar tarafından oluşturulan sanal bilgiler eklenerek geliştirilmiş/artırılmış gerçek zamanlı doğrudan veya dolaylı görünümü olarak tanımlanan Artırılmış Gerçeklik (AR), bakım onarım faaliyetleri ve robot görevlerinin tasarlanması gibi pek çok alanda kullanılır (Carmigniani, 2011).

Bulut bilişim teknolojisi, minimum yönetim çabası veya hizmet sağlayıcısıyla hızlı bir şekilde sağlanabilen ve serbest bırakılabilen, yapılandırılabilir bilgi işlem kaynakları (örneğin ağlar, sunucular, depolama, uygulamalar ve hizmetler) için paylaşılan, isteğe bağlı ă̆ erişimine olanak sağlayan bir modeldir (Dillon vd., 2010). Bulut bilişim kullanımı, işletmelere operasyonlarında hız ve esneklik sağlarken, aynı zamanda birimler arası veri paylaşımını kolaylaştırır.

Endüstri 4.0 teknolojilerinden bir diğgeri büyük veri analitiğidir. TechAmerica kuruluşunun Büyük Veri komisyonu, büyük veriyi şu şekilde tanımlar: Büyük Veri, bilgilerin toplanmasını, depolanmasını, dağıtılmasını, yönetimini ve analizini sağlamak için gelişmiş teknikler ve teknolojiler gerektiren yüksek hacimli, yüksek hızda, karmaşık ve değişken verileri açıklayan bir terimdir (Gandomi ve Haider, 2015). Makine, insan ve proseslere ilişkin büyük verinin analiz edilmesi Endüstri 4.0 faaliyetlerinin önemli bir parçasını oluşturur.

Eklemeli İmalat Sistemleri, ya da daha yaygın kullanımı ile 3 Boyutlu Yazıcılar, bir yazılım yardımı ile çeşitli malzemelerin katmanlar halinde eklenmesi ile oluşturulan üretim sistemleridir. Eklemeli imalat sistemlerinin, üretimden kaynaklanan atıkları azaltmada ve tam zamanında üretim yaparak enerji tüketimini optimum düzeyde tutmada önemli bir rol üstlenmesi beklenmektedir (Dilberoğlu, 2017).

Endüstri 4.0'ın bel kemiğini oluşturan nesnelerin interneti teknolojisi, çeşitli nesnelerin (makinalar, cihazlar, ekipmanlar) radyo-frekans tanımlama (RFID) etiketleri, sensörler, aktüatörler, cep telefonları, vb. aracılığı ile birbirleri ile iletişim kurması, iş birliği yapması ve böylece ortak hedeflere yönelmesi ilkesine dayanır (Atzori, 2010).

Endüstri 4.0 dönüşümünde bütünleşik üretimi teşvik etmenin yolu, üretimde hata payını azaltan, verimlilik seviyesinin artmasına ve sistem optimizasyonuna katkı 
sağlayan, birbirleri ile ve insanlarla etkileşim kurabilen Otonom Robotların kullanımıdır (Saucedo-Martínez vd., 2018)

İşletmelerin dijitalleşmesi siber saldırılara karşı kırılganlı̆̆ı da beraberinde getirir. Endüstri 4.0 bağlamında Siber Güvenlik, şirketlerin rekabet edebilirlik kaybının önlenmesinde öncü bir rol oynamaktadır. Yakın gelecekte siber güvenliğin Endüstri 4.0 paradigmasını benimseyen şirketlerin strateji, tasarım ve operasyonlarının ayrılmaz bir parçası olması beklenmektedir (Lezzi vd., 2018).

Simülasyon teknolojileri, iş çizelgeleme, eğitim, veri analitiği ve ürün tasarımı gibi pek çok alanda destek sağlamaktadır (Günal, 2019) Simülasyon teknolojileri imalatçı işletmelere zaman ve kaynak tasarruflu çözümler sunarak Endüstri 4.0'1n önemli bileşenlerinden birini oluşturur.

Üretim faaliyetlerini gerçekleştiren işletme içi birimler ile ürün tedarik zincirini oluşturan farklı işletmeler arasında veri, bilgi, ürün ve paranın aktarımı, bütünleşik sistemlerin eş zamanlı ve karşılıklı işleyişi ile mümkündür. Endüstri 4.0'1n Sistem Bütünleştirme prensibi, tüm sistemin doğru, hatasız ve hızlı bir şekilde bütünleştirilmesini öngörür.

\subsection{Gıda ve İçecek İmalat Sektöründe Endüstri 4.0}

Dördüncü sanayi devrimi, diğer sektörlerin yanında Gıda ve içecek imalat sektörünü yakından ilgilendirmektedir. TÜSİAD'ın yayınladığı Endüstri 4.0 raporuna göre, Gıda ve içecek sektörü, Türkiye' nin toplam üretiminde \%18'lik pay ile ilk sırada gelmekte olup, sektörde Endüstri 4.0 ile beklenen verimlilik artışı, toplam maliyetlerde \%5-9, dönüştürme maliyetlerinde ise \%9-12 aralığındadır (TÜSİAD, 2016).

Gıda ve içecek sektöründe, gerçek zamanlı veri analitiği ile tüketici talepleri daha net öngörülebilir, nesnelerin interneti sayesinde gıdanın tedarik zinciri boyunca izlenebilirliği kolaylaşır ve toplamda verimlilik artışı sağlanırken, atık miktarında düşüş gerçekleştirilir (Firat ve Firat, 2017; Alkan, 2020). Endüstriyel nesnelerin interneti teknolojisi sayesinde gıda ve içecek üreten işletmeler, üretim süreçleri boyunca paydaşları ile yoğun iletişim ve yakın işbirliği imkânı bulacaktır (Özdemir ve Özdemir, 2019). 
Gıda ve içecek sektörü, diğer sektörlerden farklı olarak hijyen ve güvenilirlik standartları gibi ek kriterlere ihtiyaç duymaktadır. Bu nedenle modern otonom robotik sistemleri ile üretim ve paketleme g1da sektörü için büyük önem taşımaktadır (Ötleş ve Özyurt, 2016).

Uzmanlar tarafından, gıda sektörünün geleceğini şekillendireceği düşünülen yaklaşımlar aşağıda sıralanmıştır (Luque, 2017):

- Nesnelerin interneti (IoT), yapay zekâ ve büyük veri

- Son nesil bileşen tasarımı için mikro kapsülleme ve nano kapsülleme

- Kalite kontrol ve gida güvenliği için kimyasal görüntü

- Gida güvenliği için yeni biyolojik yöntemler

- Gıda prosesi dönüşümü için oluşan baskı

- 21. Yüzyıl gıdalarının derisi olan aktif ambalaj

Yukarıda adı geçen modern yaklaşımların temelini Endüstri 4.0 teknolojileri oluşturmaktadir.

\subsection{Endüstri 4.0 Olgunluk Modeli}

Tüm dünyada her sektörden ve her ölçekten işletmeler, Endüstri 4.0 dönüşümünü gerçekleştirerek, bu dijital yarışta yer edinme çabası içerisindedir. Ancak her teknoloji, her işkolu için aynı önem derecesine sahip olmadığı gibi, işletmelerin bu dönüşümü gerçekleştirecek finansal, iş gücü ve bilgi kaynaklarına erişim imkânı da büyük farklılıklar göstermektedir. İşletmelerin Endüstri 4.0 prensiplerini ne derece hayata geçirdiklerine dair araştırmalar, çeşitli boyutları içeren Endüstri 4.0 olgunluk modelleri sunmaktadır. Bu olgunluk modelleri gelişimde standartlaşma, daha yüksek kalite, daha çok esneklik, sürekli klyaslama ve iyileştirme, iş alanları arasında küresel rekabet, dijitalleşme ile birlikte yaratılan yeni iş alanları, yeni hizmet alanları ve yeni iş modelleri yaratılması gibi pek çok fayda içerir (Gökalp vd., 2017). 


\section{LITERATÜR TARAMASI}

\subsection{Endüstri 4.0 Modellerine Yönelik Literatür}

Literatürde Endüstri 4.0'1n tanımsal ve kavramsal boyutuna ilişkin çok sayıda çalışma bulunmakta olmakla birlikte, uygulamaya yönelik çalışmalar toplam literatürün çok küçük bir kısmını oluşturmaktadır. Ancak son yıllarda, işletmelerin Endüstri 4.0'a ne derece hazır olduğunu araştıran modeller ile Endüstri 4.0' 1 ne derece uyguladıklarını belirlemeye yönelik E4.0 olgunluk modelleri mevcut literatürde yerini almaya başlamıştır. Bu çalışmalar incelendiğinde, Endüstri 4.0 olgunluk modelleri iki ayrı grupta toplanabilir: (1) Holistik yaklaşımlar - Endüstri 4.0 bileşenlerini mümkün olan tüm yönleri ile inceleyip, çok sayıda elementi kapsar; (2) Spesifik yaklaşımlar Endüstri 4.0'1n belirli bir yönüne odaklanarak, bu alanda derinlemesine inceleme yapar (Schumacher vd., 2019).

Endüstri 4.0 stratejileri, insan kaynağı faktörü ve yönetim yetkinliği gibi farklı boyutları bütüncül bir bakış açısı ile birleştiren holistik olgunluk modellerine örnek olarak, Lichtblau vd. (2015); Schumacher vd. (2016 ve 2019); Gökalp vd. (2017); Bibby ve Dehe (2018); Özçelik vd. (2018); Akdil vd. (2018); Santos ve Martinho (2019) tarafından geliştirilen modeller verilebilir.

Spesifik Endüstri 4.0 olgunluk modelleri ise Endüstri 4.0 uygulamalarının bilişim teknolojileri ve büyük veri kullanımı gibi belirli bir alanına yoğunlaşmış olup, Commuzzi (2016); Leyh vd. (2017); Klötzer ve Pflaum (2017); ve Nemeth vd. (2018) yazarlı çalışmalar, bu alanda yapılmış başlıca olgunluk çalışmalarıdır. Tablo 1, işletmelerin Endüstri 4.0 olgunluklarını ve Endüstri 4.0'a olan hazırlık düzeylerini değerlendiren çalışmaları özetler. 
Tablo 1. Endüstri 4.0 Hazırlığ1 ve Olgunluğuna İlişkin Mevcut Modeller

\begin{tabular}{|c|c|c|c|c|}
\hline & Yazar & Tarih & Model & Açıklama \\
\hline 12 & Lichtblau vd. & 2015 & $\begin{array}{l}\text { Holistik } \\
\text { hazırlik } \\
\text { modeli }\end{array}$ & $\begin{array}{l}\text { IMPULS- Endüstri } 4.0 \text { hazırlık modeli, altı boyut } \\
\text { altında } 18 \text { ölçekli bir araştırma sonucu sunarken aynı } \\
\text { zamanda, E.40 önündeki engelleri ve çözüm yollarını } \\
\text { da analiz etmektedir. }\end{array}$ \\
\hline 16 & Commuzzi & 2016 & $\begin{array}{l}\text { Spesifik } \\
\text { olgunluk } \\
\text { modeli }\end{array}$ & $\begin{array}{l}\text { Spesifik olarak işletmelerde büyük veri kullanımını } \\
\text { ölçmeyi hedefleyen bu olgunluk modeli, üç farklı } \\
\text { işletmede uygulanarak denenmiştir. }\end{array}$ \\
\hline 11 & $\begin{array}{l}\text { Pricewaterhouse } \\
\text { Coopers }\end{array}$ & 2016 & $\begin{array}{l}\text { Holistik } \\
\text { hazırlık } \\
\text { modeli }\end{array}$ & $\begin{array}{l}\text { Bu çalışma, işletmelerin altı boyut ile kendi kendilerini } \\
\text { değerlendirdikleri bir Endüstri } 4.0 \text { hazırlık modeli } \\
\text { sunmaktadır. }\end{array}$ \\
\hline 15 & Proença ve Borbinha & 2016 & $\begin{array}{l}\text { Literatür } \\
\text { taraması }\end{array}$ & $\begin{array}{l}\text { Bu çalışma, işletmelerin bilişim teknolojileri kullanım } \\
\text { olgunluklarını değerlendiren makalelerin tarandığı, } \\
\text { spesifik bir olgunluk araştırmasıdır. }\end{array}$ \\
\hline 1 & Schumacher vd. & 2016 & $\begin{array}{l}\text { Holistik } \\
\text { olgunluk } \\
\text { modeli }\end{array}$ & $\begin{array}{l}\text { Çalışmada ürün, müşteri, operasyon, teknoloji, } \\
\text { strateji, liderlik, yönetim, kültür ve insan boyutlarını } \\
\text { içeren bir model önerilmiştir. }\end{array}$ \\
\hline 6 & Gökalp vd. & 2017 & $\begin{array}{l}\text { Holistik } \\
\text { olgunluk } \\
\text { modeli }\end{array}$ & $\begin{array}{l}\text { Çalışma, süreç dönüşümü, yönetim uygulaması, veri } \\
\text { yönetimi, varlı yönetimi, örgütsel uyum alanları } \\
\text { başlıkları altında, işletmelerin E4.0 olgunluğunu } \\
\text { araştırmayı hedeflemektedir. }\end{array}$ \\
\hline 17 & Klötzer ve Pflaum & 2017 & $\begin{array}{l}\text { Spesifik } \\
\text { olgunluk } \\
\text { modeli }\end{array}$ & $\begin{array}{l}\text { İmalat tedarik zincirlerinde dijitalleşmeyi ölçen bir } \\
\text { olgunluk modeli öneren bu çalışma, siber-fiziksel } \\
\text { sistemler, akıllı ürünler ve büyük veri analitiği gibi } \\
\text { alanları kapsamaktadır. }\end{array}$ \\
\hline 13 & Leyh vd. & 2017 & $\begin{array}{l}\text { Spesifik } \\
\text { olgunluk } \\
\text { modeli }\end{array}$ & $\begin{array}{l}\text { Çalışma } 5 \text { boyutlu bir olgunluk modeli ile işletmelerin } \\
\text { Endüstri } 4.0 \text { olgunluklarını, bilişim teknolojileri } \\
\text { kullanım düzeylerini temel alarak değerlendirmeyi } \\
\text { amaçlamaktadır. }\end{array}$ \\
\hline 10 & Akdil vd. & 2018 & $\begin{array}{l}\text { Holistik } \\
\text { olgunluk ve } \\
\text { hazırlik } \\
\text { modeli }\end{array}$ & $\begin{array}{l}\text { Çalışmada Schumacher vd.'nin } 2016 \text { tarihli modelinde } \\
\text { kullanılan boyutlar esas alınmış olup, parekende } \\
\text { sektöründe faaliyet gösteren bir işletmede uygulama } \\
\text { gerçekleştirilmiştir. }\end{array}$ \\
\hline 7 & Bibby ve & & $\begin{array}{l}\text { Holistik } \\
\text { olgunluk } \\
\text { modeli }\end{array}$ & $\begin{array}{l}\text { Geleceğin fabrikaları, insan ve kültür ve strateji } \\
\text { boyutları temelinde, E4.0 olgunluk değerlendirmesi } \\
\text { yapmayı amaçlayan çalışma, geleceğin fabrikaları } \\
\text { için, eklemeli imalat, bulut bilişim, üretim yürütme } \\
\text { sistemi, nesnelerin interneti, siber-fiziksel sistemler, } \\
\text { büyük veri, sensörler, e-değer zinciri ve otonom } \\
\text { robotların kullanımını araştırmaktadır. }\end{array}$ \\
\hline 9 & Mittal vd. & 2018 & $\begin{array}{l}\text { Literatür } \\
\text { taraması }\end{array}$ & $\begin{array}{l}\text { Literatürde yer alan mevcut Endüstri } 4.0 \text { olgunluk } \\
\text { modellerinin incelendiği bu çalışmada, ölçekler ve } \\
\text { süreçler, küçük ve orta ölçekli işletmeler (KOBI'ler) } \\
\text { açısından yorumlanmiştır. }\end{array}$ \\
\hline 14 & Nemeth vd. & 2018 & $\begin{array}{l}\text { Spesifik } \\
\text { olgunluk } \\
\text { modeli }\end{array}$ & $\begin{array}{l}\text { Firmaların kestirimci ve önleyici bakım stratejilerinin } \\
\text { veri bilimi ile desteklenerek dijitalleşmesini hedef alan } \\
\text { çalışma spesifik bir olgunluk modeli sunmaktadır. }\end{array}$ \\
\hline 5 & Özçelik vd. & 2018 & $\begin{array}{l}\text { Holistik } \\
\text { olgunluk } \\
\text { modeli }\end{array}$ & $\begin{array}{l}\text { Çalışmada, Schumacher vd.'nin } 2016 \text { yılı } \\
\text { çalışmalarında önerilen model ve temel kriterler esas } \\
\text { alınmıştır. }\end{array}$ \\
\hline
\end{tabular}




\begin{tabular}{|c|c|c|c|c|}
\hline 8 & Castelo-Branco vd. & 2019 & $\begin{array}{l}\text { Spesifik } \\
\text { hazırlık } \\
\text { modeli }\end{array}$ & $\begin{array}{l}\text { Avrupa Birliği ülkelerinde yer alan imalatçıların E4.0 } \\
\text { adaptasyonunu ölçmeyi amaçlayan çalışma, E4.0 } \\
\text { altyapısı ve büyük veri kullanımını baz almaktadır. }\end{array}$ \\
\hline 3 & Paccini vd. & 2019 & $\begin{array}{l}\text { Spesifik } \\
\text { hazırlık } \\
\text { modeli }\end{array}$ & $\begin{array}{l}\text { Araştırmacılar, IoT, büyük veri, bulut bilişim, siber- } \\
\text { fiziksel sistemler, otonom robotlar, eklemeli imalat, } \\
\text { artırılmış gerçeklik ve yapay zeka gibi E4.0 } \\
\text { teknolojileri için işletmelerin hazırlık düzeyini ölçen } \\
\text { bir model önermiştir. }\end{array}$ \\
\hline 4 & Santos ve Martinho & 2019 & $\begin{array}{l}\text { Holistik } \\
\text { olgunluk } \\
\text { modeli }\end{array}$ & $\begin{array}{l}\text { Çalışmanın sonunda, örgütsel strateji, yapı ve kültür, } \\
\text { işgücü, akıllı fabrikalar, akıllı süreçler, akıllı ürünler ve } \\
\text { servisleri temel alan bir olgunluk modeli } \\
\text { geliştirilmiştir. }\end{array}$ \\
\hline 2 & Schumacher vd. & 2019 & $\begin{array}{l}\text { Holistik } \\
\text { olgunluk } \\
\text { modeli }\end{array}$ & $\begin{array}{l}2016 \text { yılında yapılan çalışmanın devamı niteliğindeki } \\
\text { yayında, teknoloji, ürün, müşteriler ve partnerler, } \\
\text { değer yaratma süreci, veri ve bilgi sistemleri, } \\
\text { kurumsal standartlar, çalışanlar, strateji ve liderlik } \\
\text { odaklı bir model geliştirilmiştir. }\end{array}$ \\
\hline
\end{tabular}

Kaynak: Yazar tarafından üretilmiştir.

\subsection{Endüstri 4.0 Dönüşümde AHP Metodunun Kullanımına Yönelik}

\section{Literatür}

Analitik hiyerarşi prosesi, son yıllarda, iş yaşamında diğer pek çok alanda olduğu gibi, işletmelerin Endüstri 4.0 dönüşüm süreçlerinde de karar verme mekanizmalarına sağladığı analitik destek ile uygulama alanı bulmaya başlamıştır. Aşağıda bu kullanımlara ilişkin literatür özetlenmiştir:

Özçelik ve diğerlerinin 2018 yılında gerçekleştirdikleri çalışmada, Schumacher vd. (2016) tarafından geliştirilen dokuz boyutlu holistik yaklaşıma, AHP yöntemi uygulanarak, beş düzeyli bir Endüstri 4.0 olgunluk modeli tanımlanmış ve Sakarya ilinde makine imalat sanayiinde faaliyet gösteren bir işletmenin dijital olgunluk düzeyi belirlenmiştir.

Luthra ve Mangla (2018) Hindistan imalat sanayi tedarik zincirinin E4.0 dönüşümü önündeki engelleri faktör analizi ve AHP yöntemleri ile önceliklendirerek sıralamıştır. Çalışmanın sonuçları, örgütsel engellerin öneme göre ilk sırada olduğunu, stratejik engeller ile yasal ve etik engellerin sırasıyla ikinci ve üçüncü seviyede önemli olduğunu göstermektedir.

Nesnelerin interneti ve bulut bilişim teknolojileri, işletmelerin Endüstri 4.0 dönüşümlerinin önemli bir bileşenini oluşturmaktadır. Huang ve diğerleri 2018 yılı tarihli çalışmalarında, endüstriyel nesnelerin interneti cihazları için kullanılan bulut hizmetlerinin risklerinin değerlendirilmesinde AHP metodolojisinden yararlanmıştır. 
Geliştirilen bu model ile sistemlerin güvenilirliği, bütünlüğü ve erişilebilirliği değerlendirilmiştir.

Ly vd. (2018) işletmelerde nesnelerin interneti kullanımını etkileyen faktörlerin analizinde yine AHP yönteminden yararlanmış ve analizlerden elde ettikleri bulgulara göre, güvenlik, değer ve bağlanabilirlik gibi somut faktörlerin, telebulunma ve zekâ gibi soyut faktörlerden daha önemli olduğu sonucuna ulaşmıştır.

Sevinç vd. (2018) KOBI'lerin Endüstri 4.0 adaptasyonu önündeki güçlükleri analitik hiyerarşi prosesi (AHP) ve analitik ă̆ prosesi (ANP) yöntemleri ile analiz edip, sıralamışlardır. Çalışmanın sonuçlarına göre en önemli kriter maliyet kriteri olurken, ikinci sırada organizasyon ve çevre kriterleri eşit ağırlıkla yer almıs, inovasyon kriteri ise son sırada yer almıştır.

Erbay ve Yıldırım (2019) işletmeler için Endüstri 4.0 teknolojilerinin hangilerinin daha önemli olduğunun saptanması, ayrıca E4.0 dönüşüm sürecinde öne çıkan faydaların ve zorlukların belirlenmesi süreçlerinde AHP ve kalite fonksiyon yayılımı metotlarını kullanmışlardır. Çalışmanın bulgularına göre, en önemli Endüstri 4.0 araçları sırasıyla, veri analitiği, akıllı sensörler ve üretim yönetimi yazılımları olurken, E4.0 önündeki en büyük engel uzman bilgisi eksikliği olarak belirlenmiştir.

$\mathrm{Bu}$ çalışmanın amacı gıda ve içecek imalat sektöründe, Endüstri 4.0 teknolojilerinin önem derecelerinin belirlenmesi ile Analitik Hiyerarşi Prosesi (AHP) yöntemine dayanan, sektöre özel, teknoloji odaklı bir olgunluk modeli sunmaktır. Bilindiği kadarı ile mevcut literatürde tüm Endüstri 4.0 teknolojilerini içeren, sektöre özel bir spesifik olgunluk modeli bulunmamaktadır. Bu çerçevede sunulan modelin, kapsamı ve odağı nedeni ile ulusal ve uluslararası literatürde bir ilk olduğu söylenebilir.

Çalışmanın bir sonraki bölümü, AHP metodolojisinin tanımı, kullanım alanı ve uygulama adımlarından oluşan teorik yaklaşımı açıklar. Çalışmanın üçüncü bölümü, gıda ve içecek imalatçılarının Endüstri 4.0 olgunluklarını değerlendiren bir Endüstri 4.0 olgunluk modeli ortaya koyar ve sonuçları değerlendirir. Çalışmanın son bölümü, konuya ilişkin genel çıkarımlar ile gelecek çalışmalar için önerileri içermektedir. 


\section{ARAŞTIRMA METODU}

Thomas Saaty tarafından geliştirilen Analitik Hiyerarşi Prosesi (AHP), özellikle karmaşık karar problemlerinde, alternatifler arasında, önceden belirlenmiş kriterlere göre bir sıralama yapmak ve bunların arasından en iyi alternatifi seçmek için kullanılan bir karar verme desteğidir (Jaganathan, 2007). AHP yöntemi 1980'lerde tanıtıldığından bu yana işletme yönetiminden, mühendislik problemlerine; teknoloji yönetiminden, sosyal çalışmalara kadar birçok farklı alanda ortaya çıkan seçim ve sıralama problemlerine çözüm desteği sağlamıştır. AHP'nin kullanım alanları arasında finansal kararlar, makro-ekonomik tahmin, pazarlama kararları, müşteri tercihlerinin değerlendirilmesi, ürün tasarımı kararları, ürün stratejisinin seçilmesi, planlama kararları, yatırım aracı seçimi, iş yeri seçimi, kaynakların dağıtılması, tedarikçi seçimi, yatırım projelerinin seçimi, malzeme, ekipman veya yazılım sistemi seçimi, performans ve risk değerlendirme, eğitim modeli seçimi yer almaktadır.

AHP metodolojisinin uygulama adımları en sade şekli ile aşağıdaki gibidir:

1. Seçim yapılacak karar alternatiflerinin belirlenmesi

2. Alternatiflerin seçiminde temel alınacak değerlendirme kriterlerinin belirlenmesi

3. Alternatiflerin performanslarının, mevcut kriterler çerçevesinde değerlendirilmesi

4. Kriterlerin göreceli önem derecelerinin hesaplanması

5. Yukarıdaki bilgilerin bütünleştirecek bir algoritmanın oluşturulması (Jaganathan, 2007).

AHP yöntemi ile analiz hem kriterlerin hem de alternatiflerin karşılaştırılmasını içeren, 1-9 ölçeğindeki ikili karşılaştırma matrislerine dayanır. Saaty tarafından geliştirilen, karar vericilerin tecrübe ve yargılarına dayanan temel karşılaştırma ölçeği Tablo 2' de verilmiştir. 
Tablo 2. AHP Karşılaştırma Ölçeği

\begin{tabular}{|c|l|l|}
\hline $\begin{array}{c}\text { Önem } \\
\text { Derecesi }\end{array}$ & \multicolumn{1}{|c|}{ Tanım } & \multicolumn{1}{c|}{ Açılama } \\
\hline 1 & Eşit derecede önemli & Her iki kriter aynı öneme sahiptir \\
\hline 3 & Orta derecede önemli & Bir faktör diğerine göre biraz daha önemlidir. \\
\hline 5 & Kuvvetli derecede önemli & Bir faktör diğerinden kuvvetle daha önemlidir \\
\hline 7 & $\begin{array}{l}\text { Çok kuvvetli derecede } \\
\text { önemli }\end{array}$ & $\begin{array}{l}\text { Faktörlerden biri diğerinden yüksek derecede } \\
\text { önemlidir }\end{array}$ \\
\hline 9 & Mutlak derecede önemli & $\begin{array}{l}\text { Faktörlerden biri diğerinden çok yüksek derecede } \\
\text { önemlidir }\end{array}$ \\
\hline $2,4,6,8$ & $\begin{array}{l}\text { İki değerlendirme } \\
\text { arasında kalan ara } \\
\text { değerler }\end{array}$ & $\begin{array}{l}\text { İki faktör arasındaki küçük farklar olduğunda } \\
\text { kullanılır }\end{array}$ \\
\hline \multicolumn{2}{|c}{ Kaynak: Saaty, 1987: 163 } \\
\hline
\end{tabular}

İkili karşılaştırma matrisinin genel matematiksel ifadesi aşağıda verilmiştir:

$$
A=\left[\begin{array}{cccc}
a_{11} & a_{12} & \ldots & a_{1 n} \\
a_{21} & a_{22} & \ldots & a_{2 n} \\
\ldots & \ldots & \ldots & \ldots \\
a_{n 1} & a_{n 2} & \ldots & a_{n n}
\end{array}\right]=\left[\begin{array}{cccc}
a_{11} & a_{12} & \ldots & a_{1 n} \\
1 / a_{12} & a_{22} & \ldots & a_{2 n} \\
\ldots & \ldots & \ldots & \ldots \\
1 / a_{1 n} & 1 / a_{2 n} & \ldots & a_{n n}
\end{array}\right]
$$

Burada,

$a_{i j}$ değeri, i ve j elemanları arasındaki karşılaştırma değerini ifade etmekte olup,

$$
a_{j i}=1 / a_{i j}{ }^{\prime} \text { dir. }
$$

İkili karşılaştırma matrisinden elde edilen öncelikler vektörü aşağıda gibi gösterilir:

$$
W=\left(w_{1}, w_{2}, \ldots \ldots, w_{n}\right)
$$

Burada $w_{i}$ bir değerin önceliğini veya ağırlı̆̆ını temsil eder.

$$
\begin{gathered}
\sum_{i=1}^{n} \sum_{j=1}^{n} \sum_{k=1}^{n} a_{i j} a_{j k}=a_{i k} \quad(i, j, k=1,2, \ldots, n) \\
\left|a_{i j}\right| \cdot\left|a_{j k}\right|=\left(w_{i} / w_{j}\right) \cdot\left(w_{j} / w_{k}\right)=\left(w_{i} / w_{k}\right)=a_{i k}
\end{gathered}
$$

AHP yönteminde, modeli oluşturan bileşenler arasında hiyerarşik yapının tutarlı bir şekilde oluşturulması, sonuçların doğruluğu açısından büyük önem taşır. $\mathrm{Bu}$ nedenle, karşılaştırma matrislerinin tutarlılı̆̆ı aşağıdaki adımlar takip edilerek test edilir (Timor, 2011: 44):

1. Karşılaştırma matrisinin her bir satırı için, sütunlarda yer alan elemanların ağırlıkları toplamı hesaplanır. 
2. Karşılaştırma matrisinin her bir sütunundaki eleman elde edile toplam sütun ağırlığına bölünerek normalize edilmiş matris hesaplanır.

3. Normalize edilmiş matrisin her bir satırının ortalaması alınarak öncelikler vektörü hesaplanır (A ğırlıklar bulunur).

4. Öncelikler vektörü, başlangıçta verilen karşılaştırma matrisi ile çarpilarak, tüm öncelikler matrisi oluşturulur.

5. CI tutarlılık indeksi olup aşağıdaki eşitlik ile hesaplanır:

$$
C I=\left(\lambda_{\text {maks }}-n\right) /(n-1)
$$

6. Tutarlılık oranı (CR) ise aşağıdaki şekilde bulunur:

$$
C R=C I / R I
$$

Burada $\lambda_{\text {maks }}$ bir kare matrisin özdeğerleri arasındaki en büyük değeri ifade eder. Tüm öncelikler matrisinin her bir elemanının öncelikler vektörü elamanına bölünmesi ile elde edilen yeni matris elemanlarının ortalaması alınır. Burada RI, değeri karar alternatiflerinin sayısı ile doğru orantılı olarak değişen rastgele değer indeksidir. Analizlerde oluşturulan tüm karşılaştırma matrisleri için tutarlılık oranının 0,10'dan küçük olması gereklidir:

$$
C R \leq 0,10
$$

Yukarıdaki ilk üç adım sonucu bulunan ağırlıklar, kriterlerin veya alternatiflerin göreceli önem derecelerini gösterir ve yapılacak sıralamanın temelini oluşturur.

\section{UYGULAMA VE BULGULARIN TARTIŞILMASI}

Çalışma kapsamında, g1da imalat sanayinde faaliyet gösteren 17 büyük ölçekli firma yöneticisi ile telefon görüşmeleri gerçekleştirilmiş ve Endüstri 4.0 teknolojileri hakkında görüşleri alınmıştır² ${ }^{2}$ Yapılan görüşmelerde, alacakları kararlar ile sektöre yön verme potansiyeli olan, çalışan sayısı 250 ve üzeri imalatçı işletmelerin, üretim ve operasyonlarından sorumlu yöneticileri hedef alınmıştır.

\footnotetext{
${ }^{2}$ Bu çalışmanın veri toplama aşaması 01.01.2020 tarihinden önce Aralık 2019'da gerçekleştirildiğinden, etik kurul izin belgesi gerekmemektedir.
} 
Yöneticilere, aşağıdaki Endüstri 4.0 teknolojilerinin her birinin sektörleri açısından önem derecesi sorulmuş ve yanıtlardan elde edilen aritmetik ortalamalar ile bir hiyerarşi (üstünlükler) matrisi oluşturulmuştur. Çalışmaya dahil edilen temel Endüstri 4.0 teknolojileri Tablo 3'de listelenmiştir. Karşılaştırma matrislerinde gösterim kolaylığı açısından ve uluslararası literatür ile uyum sağlamak amacı ile, terimlerin İngilizce kısaltmaları kullanılmış olup, ilgili açıklamalar karşı sütunda verilmiştir.

Tablo 3. Endüstri 4.0 Teknolojileri

\begin{tabular}{|l|l|l|}
\hline & Endüstri 4.0 Teknolojisi & Açıklama \\
\hline 1 & AR & Artırılmış Gerçeklik/ Augmented Reality \\
\hline 2 & CLOUD & Bulut Bilişim / Cloud Computing \\
\hline 3 & BD\&A & Büyük Veri Analitiği ( Big Data Analytics \\
\hline 4 & 3 D & $\begin{array}{l}\text { Eklemeli İmalat (3 Boyutlu Yazıcilar) / Additive } \\
\text { Manufacturing (3D Printing) }\end{array}$ \\
\hline 5 & IoT & Nesnelerin İnterneti / Internet of Things \\
\hline 6 & ROBOT & Otonom Robotlar / Autonomous Robots \\
\hline 7 & CS & Siber Güvenlik / Cyber Security \\
\hline 8 & SIM & Simülasyon / Simulation \\
\hline 9 & SYSTEM & Sistem Bütünleştirme / System Integration \\
\hline & & Kaynak: BCG, 2020 \\
\hline
\end{tabular}

Endüstri 4.0 teknolojilerinin g1da imalat sektörü için önem derecelerini hiyerarşik yapıda tanımlayan, başlangıç karşılaştırma matrisi Tablo 4'de gösterilmiştir. Bu tabloda, her bir teknoloji, bir karşılaştırma kriterini temsil etmektedir. 
Tablo 4. Endüstri 4.0 Teknolojileri Karşılaştırma Matrisi

\begin{tabular}{|l|c|c|c|c|c|c|c|c|c|}
\hline & ROBOT & CS & BD\&A & 3D & IoT & CLOUD & SIM & SYSTEM & AR \\
\hline ROBOT & 1 & 1 & 2 & 4 & 5 & 5 & 5 & 5 & 6 \\
\hline CS & 1 & 1 & 2 & 4 & 5 & 5 & 5 & 5 & 6 \\
\hline BD\&A & $1 / 2$ & $1 / 2$ & 1 & 3 & 4 & 4 & 4 & 4 & 5 \\
\hline 3D & $1 / 4$ & $1 / 4$ & $1 / 3$ & 1 & 2 & 2 & 2 & 2 & 3 \\
\hline IoT & $1 / 5$ & $1 / 5$ & $1 / 4$ & $1 / 2$ & 1 & 1 & 1 & 1 & 2 \\
\hline CLOUD & $1 / 5$ & $1 / 5$ & $1 / 4$ & $1 / 2$ & 1 & 1 & 1 & 1 & 2 \\
\hline SIM & $1 / 5$ & $1 / 5$ & $1 / 4$ & $1 / 2$ & 1 & 1 & 1 & 1 & 2 \\
\hline SYSTEM & $1 / 5$ & $1 / 5$ & $1 / 4$ & $1 / 2$ & 1 & 1 & 1 & 1 & 1 \\
\hline AR & $1 / 6$ & $1 / 6$ & $1 / 5$ & $1 / 3$ & $1 / 2$ & $1 / 2$ & $1 / 2$ & 1 & 1 \\
\hline
\end{tabular}

Başlangıç matrisi oluşturulduktan sonra, normalleştirme işlemi yapılarak, tüm değerlerin "0-1" aralığında ifade edilmesi sağlanmıştır. Tablo 5, normalize edilmiş karşılaştırma matrisi ile her bir kriterin hesaplanan önem derecesini göstermektedir.

Tablo 5. Normalize Matris ve Kriter Önem Dereceleri

\begin{tabular}{|l|l|l|l|l|l|l|l|l|l|l|}
\hline & ROBOT & CS & BD\&A & 3D & IoT & CLOUD & SIM & SYSTEM & AR & ÖNEM \\
\hline ROBOT & 0,269 & 0,269 & 0,306 & 0,279 & 0,244 & 0,244 & 0,244 & 0,244 & 0,207 & 0,256222 \\
\hline CS & 0,269 & 0,269 & 0,306 & 0,279 & 0,244 & 0,244 & 0,244 & 0,244 & 0,207 & 0,256222 \\
\hline BD\&A & 0,134 & 0,134 & 0,153 & 0,209 & 0,195 & 0,195 & 0,195 & 0,195 & 0,172 & 0,175778 \\
\hline 3D & 0,067 & 0,067 & 0,051 & 0,07 & 0,097 & 0,097 & 0,097 & 0,097 & 0,103 & 0,082889 \\
\hline IoT & 0,054 & 0,054 & 0,038 & 0,035 & 0,049 & 0,049 & 0,049 & 0,049 & 0,069 & 0,049556 \\
\hline CLOUD & 0,054 & 0,054 & 0,038 & 0,035 & 0,049 & 0,049 & 0,049 & 0,049 & 0,069 & 0,049556 \\
\hline SIM & 0,054 & 0,054 & 0,038 & 0,035 & 0,049 & 0,049 & 0,049 & 0,049 & 0,069 & 0,049556 \\
\hline SYSTEM & 0,054 & 0,054 & 0,038 & 0,035 & 0,049 & 0,049 & 0,049 & 0,049 & 0,069 & 0,049556 \\
\hline AR & 0,045 & 0,045 & 0,031 & 0,023 & 0,024 & 0,024 & 0,024 & 0,024 & 0,034 & 0,030444 \\
\hline
\end{tabular}


Karşılaştırmaların tutarlığının hesaplanması amacı ile başlangıç matrisi öncelikler vektörü ile çarpilarak, $\lambda_{\text {maks }}$ değeri 9,12 olarak bulunmuştur. Bu değer kullanılarak, sırası ile CI ve CR (tutarlılık) değerleri aşağıdaki şekilde elde edilmiştir:

$$
\begin{aligned}
& C I=\left(\lambda_{\text {maks }}-n\right) /(n-1)=(9,12-1) / 9-1=0,0151 \\
& R I=1,45(n=9 \text { için standart de ğer }) \\
& C R=C I / R I=0,0151 / 1,45 \\
& C R=0,01 \leq 0,10
\end{aligned}
$$

Hesaplama sonuçlarına göre, Tablo 5'de verilen karşılaştırma matrisi tutarlı olduğundan, matrisin son sütununda bulunan önem değerleri, Endüstri 4.0 teknolojilerinin g1da sektörü açısından önem derecesi olarak kabul edilir.

Sonuçlara göre, gıda imalatçları için en önemli iki teknolojinin eşit ağırlıkla $(0,256222)$ Otonom Robotlar ve Siber Güvenlik teknolojisi olduğu söylenebilir. Otonom Robotlar, işlemleri standartlaştırması, insan temasını en aza indirmesi ve merkezi olmayan karar sistemleri sayesinde beklenmeyen durumlarda esnek çözümler sunabilmesi ile g1da sektörü için oldukça büyük bir dönüşüm fırsatı yaratmaktadır. Üretilen ürünlerin insan sağlı̆̆ı ile doğrudan ilişkisinin bulunduğu ve bu sebeple, maliyet ve verimlilikte rekabet ederken, aynı zamanda hijyen, kalite ve güvenlik standartlarının en üst düzeyde önem arz ettiği g1da sektörü için dijital dönüşümün Otonom Robotların öncülüğünde olacağı beklenen bir bulgudur. Endüstriyel dönüşüm aşamasında, ürünler kadar verilerin de güvenliğinin sağlanması tüm üretim operasyonlarının devamlılı̆̆ı açısından gerekli olduğundan, Siber Güvenlik sistemlerini bu noktada önemli bir tamamlayıcı teknoloji olarak değerlendirebiliriz.

Gıda imalatçıları için ikinci sırada gelen Endüstri 4.0 bileşeni 0,175778 ağırlıkla Büyük Veri Analitiği olmuştur. Müşteri talep ve beklentilerinin tam olarak anlaşılması, hem üretimin hatasız olarak planlamasına, hem de atık miktarının en aza indirilmesine olanak sağlar. Hammadde ve ürünlerin neredeyse tamamının bozulabilir olduğu g1da sektöründe talebin doğru yönetilmesi için müşteri kaynaklı büyük verilerin toplanıp analiz edilmesi kritik bir fark yaratır. Ayrıca makine ve 
cihazlardan alınan sürekli ve eş zamanlı veri akışı, iş çizelgeleme; kaynakların paylaşımı ve bakım planlaması gibi üretimle ilgili pek çok kararda belirleyici rol oynamaktadir.

Üç Boyutlu (3D) Yazıcılar ile gerçekleştirilen Eklemeli İmalat Sistemleri 0,082889 ağırlıkla, üçüncü sırada önemli bulunmuştur. 3D Yazıcıların gıda sektöründe kullanılması, tüm üretim katmanlarının yenilebilir hammadde ile istenilen şekil ve boyutta üretimine imkân verdiğinden, Endüstri 4.0 dönüşümünün heyecan verici bir keşfidir. 3D Yazıcılar, ürün farklılaşması ve kişiselleştirilmiş ürünlerin görece düşük maliyetlerle ve yüksek hızlarda üretilmesi gibi faydalarının yanında; dağıtımcılar ve perakendeciler gibi üçüncü parti hizmet sağlayıcılarını ürün tedarik zincirinden eleyerek, ürünlerin nihai müşteriye doğrudan ulaştırılması imkânı da sunmaktadır (Porter vd., 2015).

Nesnelerin İnterneti, Bulut Bilişim, Simülasyon ve Sistem Bütünleştirme teknolojileri, 0,049556 ağırlık ile yöneticiler tarafından eşit derecede önemli olarak adlandırılmıştır. Artırılmış Gerçeklik teknolojisi ise 0,030444 ağırlık ile dokuz Endüstri 4.0 teknolojisi arasında son sıraya yerleşmiştir. Bu sıralamada, Artırılmış Gerçeklik teknolojilerinin kullanım alanları ve faydalarına ilişkin somut sektörel örneklerin kısıtlı olması etkili olabilir.

Hesaplanan kriter ağırlıkları, Endüstri 4.0 olgunluk modelinde, işletmelerin toplamda Endüstri 4.0 adaptasyon düzeylerini işaret eden göstergelere dönüştürülmüştür. Her bir teknolojinin elde edilen ağırlık (önem) derecesi, işletmenin söz konusu teknolojiyi uygulama düzeyi ile çarpılarak toplanır ve toplam bir skor elde edilir. Bu skor, işletmenin Endüstri 4.0 olgunluk düzeyini göstermektedir. Alternatif sayısının $i$, kriter sayısının j ile ifade edildiği bir modelde toplam skor aşağıdaki denklem yardımı ile hesaplanır (Jaganathan, 2007):

$$
A_{i}=\sum_{j=1}^{n} w_{j} a_{i j}
$$

Tek bir işletme (alternatif) için olgunluk skoru hesaplamak istediğimizde, ağırlıkların yerleştirilmesi ile mevcut olgunluk modeli aşağıdaki halini alır: 


$$
\begin{gathered}
A=\sum 0,26 a_{\text {robot }}+0,26 a_{c s}+0,18 a_{\text {bd\&a }}+0,08 a_{3 d}+0,05 a_{\text {Iot }}+0,05 a_{\text {cloud }} \\
+0,05 a_{\text {sim }}+0,05 a_{\text {system }}+0,03 a_{a r}
\end{gathered}
$$

Sunulan model 1-7 ölçeğinde çalışmaktadır. Örnek olarak, büyük ölçekli bir g1da imalatçısında Endüstri 4.0 olgunluk skoru hesaplanmıştır. Örnek işletme, Otonom Robotlar; Siber Güvenlik; Büyük Veri Analitiği; 3D Yazıcılar; Nesnelerin İnterneti; Bulut Bilişim; Simülasyon; Sistem Bütünleştirme ve Artırılmış Gerçeklik teknolojilerinin adaptasyon ve kullanım düzeylerini sırasıyla, “6"; ; 7 "; ; 5 " ; " 1 " ; ; “1” ; “1" ; “6" ; ve "1" olarak belirtmiştir. Bu verilere göre söz konusu işletmenin olgunluk seviyesi aşağıdaki gibi bulunmuştur:

$$
\begin{gathered}
A=\sum 0,26(6)+0,26(7)+0,18(5)+0,08(1)+0,05(6)+0,05(1)+0,05(1) \\
+0,05(6)+0,03(1)
\end{gathered}
$$

$A=5,02$

Yapılan hesaplamalar sonucu, örnek işletmenin Endüstri 4.0 olgunluğu 7 üzerinden 5,02 olarak hesaplanmış olup, Tablo 6'da verilen ölçeğe göre, işletmenin olgunluk düzeyi orta-üst seviye olarak adlandırılabilir.

Tablo 6. Gıda Sektörü Endüstri 4.0 Olgunluk İndeksi

\begin{tabular}{|l|l|}
\hline İndeks & \\
\hline 1 & E 4.0 teknolojileri uygulanmiyor \\
\hline 2 & E 4.0 teknolojileri başlangiç aşamasında \\
\hline 3 & E 4.0 teknolojileri düşük seviyede uygulanıyor \\
\hline 4 & E 4.0 teknolojileri orta seviyede uygulanıyor \\
\hline 5 & E 4.0 teknolojileri orta-üst seviyede uygulanıyor \\
\hline 6 & E 4.0 teknolojileri üst seviyede uygulanıyor \\
\hline 7 & E 4.0 teknolojileri ileri düzeyde uygulanıyor \\
\hline
\end{tabular}


Mevcut uygulama bir imalatçı için gerçekleştirilmiş olup, aynı sektörden farklı firmaların Endüstri 4.0 olgunlukları mevcut modelle eş zamanlı olarak değerlendirilebilir ve karşılaştırılabilir. Sektörün teknolojik dönüşüm alanında öncü firmaları ile diğer firmalar arasında bir kıyaslama (benchmarking) yapılarak, bu veriler, işletmelerin Endüstri 4.0 dönüşüm sürecini yönetmesinde bir kaldıraç olarak kullanılabilir.

\section{SONUÇ ve ÖNERİLER}

Endüstri 4.0 veya diğer adıyla Dördüncü Sanayi Devrimi, tüm dünyada iş yaşamında yıkıcı teknolojik değişim ve dönüşümlerle gelmektedir. Endüstri 4.0 teknolojileri, yüksek kalitede ve kişiselleştirilmiş ürünlerin düşük maliyetlerle ve yüksek hızda üretilmesine imkân verdiğinden, imalat sektöründe faaliyet gösteren işletmeler için önemli bir rekabet avantajı sunmaktadır. Türkiye'de imalat sanayiinin lokomotif sektörlerinden olan g1da ve içecek sektörü ise, Endüstri 4.0 dönüşümünün vadettiği yüksek verimlilik avantajının yanında, gıda güvenliği ve kalitesinin artırılmasına ve atık oranının azaltılmasına yönelik fırsatlar ile Endüstri 4.0' dan en yüksek faydayı sağlayacak sektörlerin başında gelmektedir.

İşletmelerin Endüstri 4.0 prensiplerini ne derece hayata geçirdikleri, Endüstri 4.0 olgunluk modelleri ile ölçülür. Bu çalışmada gıda sektöründeki imalatçı işletmelerin Endüstri 4.0 teknolojik olgunluklarını ölçen spesifik bir olgunluk modeli önerilmiştir. Literatürdeki mevcut çalışmalardan farklı olarak, bu çalışmada Endüstri 4.0'ın sadece imalat teknolojileri boyutuna odaklanılmış ve gıda sektörü yöneticilerinden alınan uzman görüşleri ile sektöre özel bir ölçek elde edilmiştir. Önerilen model, mevcut literatür ile temel aldığı kriterler bakımından, Klotzer ve Pflaum (2017) ve Paccini (2019) modelleri ile benzerlik göstermekte, ancak kullandiğ analiz yöntemi ve sektöre göre farklılaştırılmış olması nedeni ile bu çalışmalardan ayrilmaktadir.

Önerilen bu model, işletmelerin kendi öz değerlendirmelerini yapmalarında etkili bir araç olarak kullanılabilir. Bu sayede sektörün iyi uygulamaları standart olarak kabul edilerek, karşılaştırmalar ve iyileştirmeler yapmak mümkün olacaktır. Bu ölçek aynı zamanda, yeterli kaynağa ve bilgiye erişmekte güçlük çeken küçük ve orta 
ölçekli işletmelerin, Endüstri 4.0 dönüşüm stratejilerini oluştururken kullanabilecekleri bir kılavuz niteliği taşımaktadır. Bu çalışmanın strateji geliştiren karar vericiler, işletmelerin operasyon yöneticileri ve araştırmacılar açısından fayda yaratması umulmaktadır. Gelecek çalışmalar, mevcut modelin, diğer imalat sektörleri ile hizmet sektörüne adapte edilip, geliştirilmesi yönünde olabilir. 


\section{KAYNAKÇA}

Alkan, M.A., 2020, Gida Sektörü ve Endüstri 4.0, Endüstri 4.0 Platformu https://www.endustri40.com/gida-sektoru-ve-endustri-4-0/, erişim tarihi: 24.06.2020

Akdil, K. Y., Ustundag, A., \& Cevikcan, E. (2018). Maturity and readiness model for industry 4.0 strategy. In Industry 4.0: Managing the digital transformation (pp. 61-94). Springer, Cham.

Atzori, L., Iera, A., \& Morabito, G. (2010). The internet of things: A survey. Computer networks, 54(15), 2787-2805.

Bibby, L., \& Dehe, B. (2018). Defining and assessing industry 4.0 maturity levels-case of the defence sector. Production Planning \& Control, 29(12), 1030-1043.

Boston Danışma Grubu (BCG), (2020). Embracing Industry 4.0 rediscovering growth, https://www.bcg.com/capabilities/operations/embracing-Industry-4.0-rediscovering-growth.aspx.

Carmigniani, J., Furht, B., Anisetti, M., Ceravolo, P., Damiani, E., \& Ivkovic, M. (2011). Augmented reality technologies, systems and applications. Multimedia tools and applications, 51(1), 341-377.

Castelo-Branco, I., Cruz-Jesus, F., \& Oliveira, T. (2019). Assessing Industry 4.0 readiness in manufacturing: Evidence for the European Union. Computers in Industry, 107, 22-32.

Comuzzi, M., \& Patel, A. (2016). How organisations leverage big data: A maturity model. Industrial Management \& Data Systems, 116(8), 1468-1492.

Dalenogare, L. S., Benitez, G. B., Ayala, N. F., \& Frank, A. G. (2018). The expected contribution of Industry 4.0 technologies for industrial performance. International Journal of Production Economics, 204, 383-394.

Dilberoglu, U. M., Gharehpapagh, B., Yaman, U., \& Dolen, M. (2017). The role of additive manufacturing in the era of industry 4.0. Procedia Manufacturing, 11, 545-554.

Dillon, T., Wu, C., \& Chang, E. (2010). Cloud computing: issues and challenges. In 2010 24th IEEE international conference on advanced information networking and applications (pp. 27-33). Ieee.

Erbay, H., \& Yıldırım, N. (2018, August). Technology Selection for Digital Transformation: A Mixed Decision Making Model of AHP and QFD. In The International Symposium for Production Research (pp. 480-493). Springer, Cham.

Furat, S., \& Fırat, O. (2017). Gıda ve İçecek Sektöründe Endüstri 4.0 Devrimi: Otomasyon ve Robotlar. ST Robot Yatırmmlarn, 216.

Gandomi, A., \& Haider, M. (2015). Beyond the hype: Big data concepts, methods, and analytics. International journal of information management, 35(2), 137-144.

Gökalp, E., Şener, U., \& Eren, P. E. (2017, October). Development of an assessment model for industry 4.0: industry 4.0-MM. In International Conference on Software Process Improvement and Capability Determination (pp. 128-142). Springer, Cham.

Gunal, M. M. (Ed.). (2019). Simulation for Industry 4.0: Past, Present, and Future. Springer. 
Huang, Y. L., \& Sun, W. L. (2018, July). An ahp-based risk assessment for an industrial iot cloud. In 2018 IEEE International Conference on Software Quality, Reliability and Security Companion (QRS-C) (pp. 637638). IEEE.

Jaganathan, S., Erinjeri, J. J., \& Ker, J. I. (2007). Fuzzy analytic hierarchy process based group decision support system to select and evaluate new manufacturing technologies. The International Journal of Advanced Manufacturing Technology, 32(11-12), 1253-1262.

Jazdi, N. (2014, May). Cyber physical systems in the context of Industry 4.0. In 2014 IEEE international conference on automation, quality and testing, robotics (pp. 1-4). IEEE.

Klötzer, C., \& Pflaum, A. (2017). Toward the development of a maturity model for digitalisation within the manufacturing industry's supply chain.

Lichtblau, K., Stıch, V., Bertenrath, R., Blum, R., Bleider, M., \& Millack, A. (2017). IMPULS, Industry 4.0 readiness, VDMA.

Lu, Y. (2017). Industry 4.0: A survey on technologies, applications and open research issues. Journal of industrial information integration, 6, 1-10.

Luque, A., Peralta, M. E., De Las Heras, A., \& Córdoba, A. (2017). State of the Industry 4.0 in the Andalusian food sector. Procedia Manufacturing, 13, 1199-1205.

Luthra, S., \& Mangla, S. K. (2018). Evaluating challenges to Industry 4.0 initiatives for supply chain sustainability in emerging economies. Process Safety and Environmental Protection, 117, 168-179.

Ly, P. T. M., Lai, W. H., Hsu, C. W., \& Shih, F. Y. (2018). Fuzzy AHP analysis of Internet of Things (IoT) in enterprises. Technological Forecasting and Social Change, 136, 1-13.

Mittal, S., Khan, M. A., Romero, D., \& Wuest, T. (2018). A critical review of smart manufacturing \& Industry 4.0 maturity models: Implications for small and medium-sized enterprises (SMEs). Journal of manufacturing systems, 49, 194-214.

Nemeth, T., Ansari, F., Sihn, W., Haslhofer, B., \& Schindler, A. (2018). PriMa-X: A reference model for realising prescriptive maintenance and assessing its maturity enhanced by machine learning. Procedia CIRP, 72, 1039-1044.

Ötleş S. Ve Özyurt, V.H. https://egeplm.ege.edu.tr/files/egeplm/icerik/endustri40_dunya_gida.pdf, Erişim tarihi: 24.06.2020.

Ozç,elik, T. O., Erkollar, A., \& Cebeci, H. I. (2019). Bir Imalat Ișletmesi için Endüstri 4.0 (Dijital) Olgunluk Seviyesi Belirleme Uygulaması. 5th International Management Information Systems Conference, Ankara.

Özdemir, Ö.ve Özdemir, E. G. Endüstri 4.0 ve yiyecek içecek işletmelerindeki yansımaları. (2019) Nevşehir HBV Üniversitesi Turizm Fakültesi, IV. International Gastronomy Tourism Studies Congress, 87-93.

Özenir, İ., \& Nakıboğlu, G. (2019). Sürdürülebilir üretimde Endüstri 4.0’1n yeri. Business E Management Studies: An International Journal, 7(5), 2248-2281.

Pacchini, A. P. T., Lucato, W. C., Facchini, F., \& Mummolo, G. (2019). The degree of readiness for the implementation of Industry 4.0. Computers in Industry, 113, 103125. 
Porter, K., Phipps, J., Szepkouski, A., Abidi, S.(2015). 3D opportunity serves it up: Additive manufacturing and food. Deloitte University Press. https://www2.deloitte.com/content/dam/insights/us/articles/3d-printing-in-the-foodindustry/DUP_1147-3D-opportunity-food_MASTER1.pdf. Erişim tarihi: 26.06.2020

Pricewaterhouse Coopers, P. (2016). Industry 4.0-Enabling Digital Operations Self Assessment. https://i40-self-assessment.pwc.de/i40/landing/, Erişim tarihi: 19.06.2020.

Proença, D., \& Borbinha, J. (2016). Maturity models for information systems-A state of the art. Procedia Computer Science, 100, 1042-1049.

Saaty, R. W. (1987). The analytic hierarchy process - what it is and how it is used. Mathematical modelling, 9(3-5), 161-176.

Santos, R. C., \& Martinho, J. L. (2019). An Industry 4.0 maturity model proposal. Journal of Manufacturing Technology Management.

Saucedo-Martínez, J. A., Pérez-Lara, M., Marmolejo-Saucedo, J. A., Salais-Fierro, T. E., \& Vasant, P. (2018). Industry 4.0 framework for management and operations: a review. Journal of ambient intelligence and humanized computing, 9(3), 789-801.

Schumacher, A., Erol, S., \& Sihn, W. (2016). A maturity model for assessing Industry 4.0 readiness and maturity of manufacturing enterprises. Procedia Cirp, 52(1), 161-166.

Schumacher, A., Nemeth, T., \& Sihn, W. (2019). Roadmapping towards industrial digitalisation based on an Industry 4.0 maturity model for manufacturing enterprises. Procedia Cirp, 79, 409-414.

Sevinc, A., Gür, Ş., \& Eren, T. (2018). Analysis of the difficulties of SMEs in industry 4.0 applications by analytical hierarchy process and analytical network process. Processes, 6(12), 264.

Sony, M., \& Naik, S. (2019). Key ingredients for evaluating Industry 4.0 readiness for organisations: a literature review. Benchmarking: An International Journal.

Timor, M. (2011). Analitik Hiyerarşi Prosesi. Türkmen Kitabevi, Ankara.

TÜSİAD, 2016, Türkiye'nin Sanayi 4.0 Dönüşümü, https://tusiad.org/tr/yayinlar/raporlar/item/8671-turkiyenin-sanayi-40-donusumu

Yaşar, E., \& Ulusoy, T. (2019). Industry 4.0 and Turkey. Business \& Management Studies: An International Journal, 7(1), 24-41. 